\title{
PREVALENCE OF CARCINOMA IN SYMPTOMATIC GALL STONE DISEASE- A STUDY FOLLOWING CHOLECYSTECTOMY
}

Manisha Nigam¹, Renu Ranwaka², Brijendra Nigam³, Mahendra Singh4,T. P.Devpura5 ${ }^{5}$

\author{
1. Assistant Professor. Department of Surgery, Rama Medical College, Mandhna, Kanpur. \\ 2. Professor, Department of Surgery, Rama Medical College, Mandhna, Kanpur. \\ 3. Laparoscopic \& General. Surgeon, MB Super speciality Hospital. Kanpur. \\ 4. Professor, Department of Pathology, GSVM Medical College. Kanpur. \\ 5. Professor, Department of Surgery, Rama Medical College, Mandhna, Kanpur.
}

\section{CORRESPONDING AUTHOR: \\ Dr. Manisha Nigam, \\ 13 Hemant Vihar, \\ Sector -3, Barra-2, \\ Kanpur: 208027. \\ E-mail: brijendramanisha@yahoo.com}

\section{HOW TO CITE THIS ARTICLE:}

Manisha Nigam, Renu Ranwaka, Brijendra Nigam, Mahendra Singh, T.P. Devpura. "Prevalence of Carcinoma in Symptomatic Gall Stone Disease- A study following Cholecystectomy". Journal of Evolution of Medical and Dental Sciences 2013; Vol2, Issue 25, June 24; Page: 4554-4558.

ABSTRACT: OBJECTIVE- To determine the prevalence of carcinoma of the gallbladder in the specimens following routine cholecystectomy. STUDY DESIGN- Observational case series study

Place \& Duration of study- Department of Surgery, Rama Medical college Hospital and Research center, from April 2009 to March 2013. MATERIALS AND METHOD-All patients with symptomatic gallstone disease of both sex having age range between 15 to 70 year were included. Patients with pre diagnosed Gallbladder malignancy, Gallbladder mass, Empyema Gallbladder and Gallstones associated with obstructive jaundice were excluded. All cholecystectomized gall bladder specimens were sent for histopathological examination. RESULTS-Five hundred and twenty patients (520) including 104 males and 416females (M: F ratio 1:4) aged15-70 year and having a mean age of 41.7 year ( \pm SD 2.4), were included in this retrospective study. Commonest presentations were pain in the right hypochondrium and a positive Murphy's sign (87.71\%) followed by dyspepsia (55\%), nausea, vomiting (40\%), pyrexia (31.92\%) and weight loss $(05 \%)$. Twenty two $(4.23 \%)$ patients had a diagnosis of malignancy of gallbladder at histopathology examination. Mean age for patients with malignancy was 55.25 year with a male to female ratio of 01:10. Well differentiated adenocarcinoma was reported in $45.45 \%$ cases, moderately differentiated in $36.36 \%$, poorly differentiated in $09.09 \%$ and undifferentiated in $09.09 \%$ patients

CONCLUSION-Though early detection and treatment has declined the incidental Gall Bladder carcinoma occurrence, but routine histopathology of cholecystectomized Gall Bladder is necessary for early detection of Gall Bladder Cancer.

KEY WORDS-Cholecystectomy, Gallstones, Histopathology.

INTRODUCTION: The prevalence of gallbladder cancer, the commonest biliary malignancy, shows geographical and racial variations. It is reported to be rare in India. However, the incidence 
of gallbladder cancer in north and central India is very high. It is one of the commonest biliary tract malignancies and ranked fifth amongst the all gastrointestinal cancers in women.1,2 The incidence of gallbladder cancer parallels the prevalence of gall stone disease; large and long-standing gall stones being associated with a higher risk of gallbladder cancer. The association of GBC with gall stone increases the risk from 4 to 7 times than those without gall stone.$^{2}$ Gall stone disease is common in north India and occurs at a younger age than in the western populations. Moreover, patients with gall stone disease present for treatment a long time after the onset of symptoms. Both these factors result in prolonged exposure of the gallbladder to stones. Besides gall stone disease, various other factors may also play a role in the causation of gallbladder cancer which is an (north) Indian disease. Mention may be made of chronic cholecystitis, Salmonella typhi infection, BMI, dietary and environmental factors as some risk factors other than gall stone. ${ }^{3}$ Among other Risk factors for carcinoma gallbladder include cholelithiasis, adenomatous polyps of the gallbladder, gallbladder wall calcification, choledochal cysts and chemical carcinogens. ${ }^{7}$

Gender wise it is more frequent in females and the highest incidence is noticed in the sixth and seventh decades of life, 1-4 Gallstones are a consistent feature in 60-95\% patients with Gallbladder cancer. Various studies have quoted a frequency of 6-28\% carcinoma gallbladder in patients with gall stone disease. ${ }^{5}$, Gallbladder cancer is usually an incidental finding, diagnosed on histological examination following cholecystectomy for cholelithiasis. ${ }^{4}$ Majority of the gallbladder carcinomas are adenocarcinomas, others less common are papillary carcinomas, well differentiated to poorly differentiated infiltrating carcinomas and squamous cell carcinomas. ${ }^{4}$ The purpose of this study was to find out the frequency of gallbladder carcinoma in specimens following cholecystectomy for gall stone disease.

METHODOLOGY: This retrospective study was carried out at Rama Medical College and research Center Kanpur from the period April 2009 to March 2013. The study was approved by Institutional Ethics Committee. We included information on the Histopathological diagnosis of all the 520 patients of gall bladder stone disease patients who were admitted for treatment during the above period.

Patients with diagnosed gallbladder malignancy, gallbladder mass, empyema, gallstones with associated obstructive jaundice and those patients who did not complete the follow-up schedule were excluded. Detailed history and clinical examination and necessary investigations were performed including blood complete picture, liver function tests and ultrasound abdomen. All the patients' underwent open/laparoscopic cholecystectomy and the gallbladder specimens were sent for histopathological study. Patients with positive histology for carcinoma were followed up in OPD at two weeks, two months and six months after surgery. Data was collected and analyzed through SPSS version 11. 


\section{ORIGINAL ARTICLE}

Table I

\begin{tabular}{|lll|}
\hline Age in year & Number of Patients & Malignancy \\
\hline $15-30$ & $50(9.61 \%)$ & 00 \\
\hline $31-40$ & $106(20.38 \%)$ & 00 \\
\hline $41-50$ & $218(41.92 \%)$ & $08(3.66 \%)$ \\
\hline $51-60$ & $96(18.46 \%)$ & $08(8.33 \%)$ \\
\hline $61-70$ & $50(9.61 \%)$ & $06(12.00 \%)$ \\
\hline Total 520 & $(100 \%)$ & $22(4.23 \%)$ \\
\hline
\end{tabular}

RESULTS: In this study of 520 patients, 104 were males and 416 females, having a male to female ratio of $1: 4(\mathrm{M}: \mathrm{F}=1: 4)$. Mean age was 41.7 year ( \pm 2.4 year) with majority of patients falling in age group of 51- 60 year(12.0\%) table 1.

The most frequent clinical presentation was pain in right hypochondrium and a positive Murphy's sign in 446 (85.71\%) patients followed by dyspepsia in 286 (55\%), nausea and vomiting in 208 (40\%), pyrexia in $166(31.92 \%)$ and weight loss in $26(5 \%)$ cases. Table II.

Table II

\begin{tabular}{|lcc|}
\hline Symptoms & No. of Patients & Percentage (\%) \\
\hline Pain in Rt. Hypochondrium & 446 & 85.71 \\
\hline Dyspepsia & 286 & 55.0 \\
\hline Vomiting Nausea & 208 & 40.0 \\
\hline Pyrexia & 166 & 31.92 \\
\hline Weight Loss & 26 & 05.0 \\
\hline
\end{tabular}

Four hundred and ninety eight (95.76\%) patients had non-neoplastic inflammatory gallbladder disease and 22 (4.23\%) patients had a positive histology for neoplastic gallbladder lesion. Age for malignancy varied from 41 to 70 year with mean age of 55.25year and male to female ratio of 1:10 (M:F=1:10).In 22(4.23\%) patients with a positive histopathology for neoplastic lesions, 10 (45.45\%) cases were diagnosed as well differentiated adenocarcinoma(table III).

Table III

\begin{tabular}{|lcc|}
\hline \multicolumn{1}{|c|}{ Tumor Grade } & No. of Patients & Percentage (\%) \\
\hline (Adenocarcinoma) & & \\
\hline Well Differentiated & 10 & $45.45 \%$ \\
\hline Moderately Differentiated & 08 & $36.36 \%$ \\
\hline Poorly Differentiated & 02 & $9.09 \%$ \\
\hline Undifferentiated 02 & 02 & $9.09 \%$ \\
\hline
\end{tabular}

Gall bladder cancer is the most common amongst gastrointestinal tract cancers followed by oral cavity and colorectal. It is usually an incidental finding following surgery for the gallstone 
disease. In its early stages, the disease has non-specific clinical presentation and its confirmation is not possible until after surgical removal of the gallbladder. Diagnosed at early stage, this cancer carries an excellent prognosis of five years survival rates between $90-100 \% .{ }^{9}$

In the current series of 520 patients who underwent routine Laparoscopic or open cholecystectomy for gallstone disease, the incidence of primary gallbladder malignancy was $4.23 \%$ which is almost comparable to other studies in the region but these values are higher as compared to $1-3.3 \%$ reported from other Western countries. ${ }^{12-14}$ Among the twenty two patients with positive histology, twenty (90.90\%) were females and two (9.09\%) male patient (M: F-1:10). Similarly an international study has reported a figure of 1:14.16.The mean age for gallbladder cancer in our study was 55.25 year which is comparable to that reported by Haq I et al. ${ }^{16}$ It is comparable to an international study quoting 56.25 year. ${ }^{17}$ Gallstones are a well established risk factor for the development of gallbladder cancer. This association has been well emphasized by Daphna et al as gallstones are present in $70-92 \%$ of patients with carcinoma gallbladder. ${ }^{18}$ The reason being that gallstones cause recurrent irritation and inflammation of the gallbladder leading to mucosal dysplasia and with passage of time to malignancy in older age group. ${ }^{12}$ The relationship of gallstones duration and development of gallbladder carcinoma has been well emphasized.11 In the present study all the incidental carcinomas were reported in symptomatic patients and histopathologically diagnosed as adenocarcinoma, being graded from well differentiated to undifferentiated types. Majority of the primary incidental carcinomas were reported to be in early stages and well differentiated. Almost similar findings have been reported by Tantiaet al 17 and Vincenzo et al. ${ }^{19}$ Decision regarding further management of incidental carcinomas of gallbladder depends upon the stage of the disease and general fitness of the patient. Complete surgical resection, when performed at an early stage of the cancer, remains the only potential curative treatment. ${ }^{20}$ Chemotherapy and radiotherapy having a role as an adjuvant treatment for gallbladder cancer, remains unestablished. ${ }^{20}$ It is well justified that routine histopathology of all gallbladder specimen following cholecystectomy for gallstone disease be performed, as incidental carcinoma finding, definitely affects the management and thus the clinical outcome.

\section{ACKNOWLEDGEMENTS:}

1. Prof. R. K. Srivastava, Principal and Dean, Rama Medical College Hospital and Research center for providing financial and material support.

2. Ms. Monika and Ms. Rajni of Rama Medical college for help in preparing manuscript

3. Hospital and O.T. staff of Rama Medical College for assisting and help in operations.

\section{REFERENCES:}

1. Kapoor VK, McMichael AJ. Gallbladder cancer: an 'Indian' disease. Natl Med JIndia. 2003 JulAug; 16(4):209-13. PubMed PMID: 14606770.

2. Nervi F., Duarte I., Gomez G, Rodríguez G, Pino G D, Ferrerio 0 et. al. Frequency of gall bladder cancer in Chile, a high risk area. International Journal of Cancer. 1988; (41) 657660.

3. M.A. Barbhuiya, T.D. Singh, S. Gupta, B.R. Shrivastav, P. K. Tiwari: Incidence of gall bladder cancer in rural and semi-urban population of north central India: A first insight. The Internet Journal of Epidemiology. 2009 Volume 7 Number 2. DOI: 10.5580/22ff 
4. Crawford JM. The liver and the biliary tract, In Kumar V, Abbas AK, Fansto N (Ed) Robbins and Cotran Pathological basis of disease.7t h Edition. 2005: 877-938.

5. Have PC, Simpson KJ, Garden OG. Liver and biliary tract disease In Hasle C, Chilvers ER, Boon NA, Colldge NR.19th Edition, Churchill Livingstone:831-88..

6. Moosa FA, Sultan N, Ahmed S, Hafiez M. Incidence of carcinoma gallbladder discovered on routine histopathology after cholecystectomy for cholelithiasis. Med Channel. 2002;8:15-7.

7. Manouras A, Genetzakis M, Lagoudianakis EE, Markoginnakis H. Undifferentiated giant cell type carcinoma of gallbladder with sarcomatoid dedifferentiation: a case report and review of the literature. J Med Case Reports. 2009; 3: 696.

8. Yamaguchi K, Tsuneyoshi M. Subclinical gallbladder carcinoma. Am J Surg. 1992; 163:382-6.

9. Misra MC, Guleria S. Management of carcinoma gallbladder found as a surprise on resected gallbladder specimen. J SurgOncol. 2006;93:690-8.

10. Naqvi SHQ, Mangi IH, Dahri FJ, Khaskhel QA, Akhund AA. Frequency of carcinoma gallbladder in patients with cholelithiasis. Gomal J Med Sci. 2005; 3:41-3.

11. Malik KA, Jawaid M. Incidental gallbladder carcinoma in patients undergoing cholecystectomy for cholelithiasis. Pak J Surg. 2009; 25:262-5. 12. Shrestha R, Tiwari M, Ranabhat SK, Aryal G, Ranniyar SK, Shrestha HG. Incidental gallbladder carcinoma: value of routine histological examination of the cholecystectomy Specimens. Nepal Med Coll J. 2010; 12: $90-4$.

12. Zhang WJ, Xu FG, Zou XP, Wang WB, Yu JC, Wu GZ. Incidental gallbladder carcinoma diagnosed during or after laparoscopic cholecystectomy. World J Surg. 2009; 33:2651-6.

13. Kwon AH, Imamura A, Kitade H, Kamiyama Y. Unsuspected gallbladder cancer diagnosed during or after laparoscopic cholecystectomy. J Surg Oncol. 2008; 77: 241-5.

14. Mohammad RS, Khan IN, Abbas QS, Khan IO. Pattern of gallbladder disease in Pakistan: an audit of 163 consecutive patients operated at a teaching hospital. Specialist Pak J Med Sci. 1999; 15:109-12.

15. Kwon SY, Chang HG. A clinicopathological study of unsuspected carcinoma gallbladder. J Korean Med Sci. 1997; 12:519-22.

16. Haq MI, Hussain M, Ikramullah, Iqbal Z. Frequency of carcinoma in cholecystectomies performed forsymptomatic gallstones. Ann Pak Inst Med Sci. 2011; 7:75-8.

17. Tantia O, Jain M, Khanna S, Sen B. Incidental carcinoma gallbladder during laparoscopic cholecystectomy for symptomatic gallstone disease. Surg Endosc. 2009; 23: 2041-6.

18. Daphna W, Mehrdad H, NoaBJ, Sandbanand AH. Incidental finding of gallbladder carcinoma. Israel Med Assoc J. 2002; 4:334-6.

19. Vincenzo C, Enrico F, Cristina P. Early gallbladder carcinoma: a single center experience. Tumor. 2006; 92:487-90.

20. Wagner AD, Buechner Stendel P, Moehler M, Schnalenberg H. Gemcitabine, oxaliplatin and 5FU in advanced bile duct and gallbladder carcinoma: two parallel, multicentre phase -II trials. Br J Cancer.2009; 101:1846-52. 